\title{
Investigation of some virulence factors associated with E. coli isolated from diarrheic buffalo calves
}

\author{
F. M. Ghanem ${ }^{1}$, M. N. El-Sheery' ${ }^{1}$ K. M. Ibrahim ${ }^{1}$, A. M. El-Sherif ${ }^{2}$ \\ ${ }^{1}$ Department of Veterinary Medicine, Faculty of Veterinary Medicine Suez Canal University \\ ${ }^{2}$ Deptment of Veterinary Medicine, Faculty of Veterinary Medicine, Beni-Suef University, Beni-Suef, Egypt
}

In this study a total of 120 diarrheic buffalo calves were examined clinically and bacteriologically was investigated. The role of $E$. coli in diarrheic buffalo calves. $E$. coli, could be isolated from $31(25.80 \%)$ calves. $K_{99}$ antigen could be detected in $(\mathbf{1 2 . 9 0 \% )}$ isolates. Studying some virulence factors of $E$. coli isolates revealed that 28 (90.30) isolates showed congored binding, $29(93.50 \%)$ isolates were able to survive in serum and $23(74.19 \%)$ were able to grow in calf serum, $25(80.64 \%)$ isolates could be proved as enterotoxin producers and caused accumulation of fluids in the intestinal tract of the inoculated mice. In addition, $28(90.30 \%)$ were able to produce verotoxins. The present study demonstrated the correlation between the presence of different virulence factors in $E$. coli isolates and its pathogenicity to newborn calves and its role in diarrheic calves.

Samples. Fecal swabs were collected from the rectum of 120 diarrheic buffalo calves.

Media. Different media were used for isolation and identification of $E$. coli. These include neutrient broth (Oxoid), nutrient agar (Oxoid), blood agar (Difco), MacConkey's agar (Oxoid) and eosin methylene blue (Oxoid). Media for congo red binding activity, serum resistance and verocytotoxicity test were obtained from (Oxoid). Medium for enterotoxin assay was obtained from (Difco).

Antisera. $\mathrm{K}_{99}$ antisera were prepared in rabbits using standard $\mathrm{K}_{99}$ antigen. Diagnostic E. coli antisera (O) and $(\mathrm{K})$ were obtained from (Welcom), Calves serum was used for serum resistance test.

Vero cells. (green monkey kidney cells) were used in verocytotoxicity test.

Identification of $\boldsymbol{E}$. coli isolates. It was carried out according to (Cruickshank et al. 1975 and Konemann et al., 1993).

Serological typing of $E$. coli agglutination test. It was carried out according to (Edwards and Ewing 1972).

Congo red binding test. It was carried out according to (Berkhoff and Vinal 1986).

Enterotoxin assay using infant mouse test. It was carried out according to (Robins-Brown et al., 1993).

Serum resistance test. It was carried out according to (Barrow and Hill 1989).

Cytotoxicity assay. It was carried out according to (Emery, et al., 1992).
Enteritis in newborn calves still represents a serious problem for the livestock production resulting in severe economic losses due to high morbidity and mortality, (Adesiyun et al., 2001). Control of calf diarrhea is usually a difficult task due to the multifactorial nature of the problem including the immunological and nutritional status of newborn calves, environmental conditions and involvement of different types of etiological agents (Aly and Sohair 1999).

Pathogenic strains of E. coli are considered the major cause of neonatal diarrhea (Khan and Khan 1997), due to the combination of different virulence factors including the ability to produce enterotoxins, vesotoxins and the expression of specific adhesions that enable the organism to colonize the intestinal epithelium.

The present study was carried out to investigate the role of pathogenic E. coli in diarrheic buffalo calves as well as the virulence factors associated with $E$. coli isolated from clinical cases including Congo red binding activity, serum resistance, enterotoxigenicity using infant mouse assay and cytotoxicity using vero cells.

Animals.

\section{Material and Methods}

Calves. A total of 120 diarrheic buffalo calves were used in this study.

Mice. 1-4 days old Swiss albino white suckling mice of were used for detection of enterotoxigenic activity of $E$. coli isolates. 


\section{Results and Discussion}

Table (1): Results of $E$. coli isolation from diarrheic calves.

\begin{tabular}{cccc}
\hline \multirow{2}{*}{ No. of calves } & \multicolumn{2}{c}{ No. of isolates } & \multirow{2}{*}{$\mathbf{K}^{99}+$} \\
\cline { 2 - 3 } & $\mathbf{1 - 1 4}$ days & $\mathbf{1 5 - 3 0}$ days & \\
\hline $\mathbf{1 2 0}$ & $24(20 \%)$ & $7(5.84 \%)$ & $4(12.90 \%)$ \\
Total & \multicolumn{2}{c}{$31(25.80 \%)$} & \\
\hline
\end{tabular}

Table (2): Serotyping of $E$. coli isolates.

\begin{tabular}{cc}
\hline Serotypes & Number \\
\hline $055 \mathrm{~K}_{59}$ & 16 \\
$026 \mathrm{~K}_{60}$ & 7 \\
$0125 \mathrm{~K}_{70}$ & 4 \\
$0114 \mathrm{~K}_{90}$ & 2 \\
$0128 \mathrm{~K}_{67}$ & 1 \\
$0111 \mathrm{~K}_{58}$ & 1 \\
Total & 31 \\
\hline
\end{tabular}

Table (3): Detection of some virulence factors of $E$. coli isolates.

\begin{tabular}{ccc}
\hline No. of isolates & Virulence factors & Positive strains \\
\hline & Congo red binding & $28(90.30 \%)$ \\
& Survival in calf serum & $29(93.50 \%)$ \\
31 & Growth in calf serum & $23(74.19 \%)$ \\
& Heat stable toxins & $25(80.60 \%)$ \\
& Vero cells cytotoxicity & $28(90.30 \%)$ \\
\hline
\end{tabular}

E.coli isolates revealed the presence of 6 serotypes, $055 \mathrm{~K}_{59}$ (16 isolates), $026 \mathrm{~K}_{60}(7$ isolates), $0125 \mathrm{~K}_{70}$ (4 isolates), $0114 \mathrm{~K}_{90}$ (2 isolates), $0128 \mathrm{~K}_{67}$ (one isolate) and $0111 \mathrm{~K}_{58}$ (one isolate), Table (2). Similar serotypes were reported by Adel et al. (1987) from buffalo calves that indicate the high prevalence of such serotypes and magnify their role in development of enteritis among buffalo calves. The results of Congo red binding of E. coli isolates revealed that $28(90.30 \%)$ were positive (Table 3). Such finding indicated a positive correlation between the isolation of congo red positive $E$. coli and the development of enteritis as reported by (Styles and Flamer 1991).

Results of serum resistance of $E$. coli isolates revealed that $29(93.50 \%)$ survived in calf serum and $23(74.19 \%)$ were able to grow in calf serum. The ability of $E$. coli organism to survive and grow in serum in spite of the bactericidal activity of complement has been

\section{Discussion}

The present study was carried out on 120 buffalo calves that showed variable degrees of diarrhea, depression and dehydration.

Bacteriological examination of fecal swabs of buffalo calves, revealed isolation of $E$. coli from $31(25.80 \%)$ calves including 24 of 1-14 days old and 7 of 15-30 days old (Table 1). Such findings agreed with that reported by (Adesyuen et al. 2001) who concluded that the prevalence of infection is higher in younger than older calves. They added that diarrhea resulted from $E$. coli infection is the outcome of interplay between the pathogen and the status of immunity at this age. In order to establish a good status of immunity, Larsson, (1995) recommended that Calf should take $2 \mathrm{~kg}$ colostrum from the first milking within five hours after birth. $\mathrm{K}_{99}$ antigen is responsible for adhesion of the organism to the intestinal mucosa of diarrheic calves, (Yadav and Bhatia 2002). Serological typing of the 31 
(STa) with its putative receptor on the intestinal tract of new calves. FEMS Immun. Med. Microbial., 28 (2): 97104.

Aly, S. and Sohair, Z. (1999): Acute enteritis in neonatal Friesian calves in Sohag Governorate with special reference to etiology, clinico biochemical and therapy. Assuit Vet. Med. J., 40 (80): 156-166.

Ball, H. J.; Finlay, D.; Burns, L. and Mackie, D. P. (1994): Application sandwich ELISA to detect verotoxins in cattle faecces. Res. Vet. Sci., 57 (2): 225-232.

Barrow, P. A. and Hill, A. W. (1989): The virulence characteristics of strains of $E$. coli isolated from cases of bovine mastitis in England and Wales. Vet. Microbiol., 20 (1): 35-48.

Berkhoff, H. A. and Vinal, A. C. (1986): Congo red medium to distinguish between invasive and non-invasive E. coli pathogenic for poultry. Avian Dis., 30(1): 117-121.

CruickShank, R.; Dugiud, J. P.; Marmoin, B. P. and Swain, R. H. A. (1975): In Medical microbiological $12^{\text {th }}$ ed. Churchil liviningston Edinburgh, London and New York.

Edwards, P. R. and Ewing, W. H. (1972): Identification of enterobacteriaceae, $3^{\text {rd }}$ ed. Burgetis, pub. Co. USA.

Emery, D. A.; Nagaraja, K. V.; Shaw, D. P.; Newman, J. A. and White, D. G (1992): Virulence factors of E. coli associated with colisepticemia in chickens and turkeys. Avian Dis., 36:504-511.

John, M.; Tacques, M. and Lariviere, S. (1989): Pathogenisty of E. coli O115: kv 165 strains isolated from pigs with diarrhea. Am.J. Vet. Res., 50 (1): 1029-1036.

Khan, A. and Khan, M. (1997): Bacteria isolated from natural cases of buffalo and bovine neonatal calf diarrhea. Vetrinarski Arhiv, 47: 161-167.

Konemann, E. W.; Allen, S. D.; Dowell, V. R. and Sommers, H. M. (1993): In color atlas and textbook of diagnostic microbiology $4^{\text {th }}$ ed., J.B.Lippincott Co., New York.

Larsson, B. (1995): The newborn calf the importance of adequate colostrum feeding. In Proc. Allmant Vet. Assoc. Stockholm, Swede, pp. 287.

Robins-Brown, R. M.; Takeda, R. M. and Fasano, T. (1993): Assement of enterotoxin production by Yersinia enterocolitica produced by non-invasive Yersenia enterocolitica strains isolated from clinical and material.

Styles, D. K. and Flammer, K. (1991): Congo red binding of $E$. coli isolated from the cloaca of psittacine birds. Avian Dis., 35: 46-48.

Tanois, A. I.; Zaki, E. R.; El-Shernoby, R; Shabrawy, M.A and Seleim, R.S. (2000): Role of enteric bacteria in etiology of neonatal buffalo calves diarrhea. Vet. Med. J. Giza, 48 (1): 56-72.

Yadav, S.K. and Bhatia, A.K. (2002): Purification and characterization of $\mathrm{K}_{99}$ antigen produced from pathogenic E. coli. Indian Vet. J., 79 (1): 11-12. considered as an important attribution to its pathogenicity. It is also suggests the possibility of its multiplication in blood, (John, et al., 1989).

In this study 25 isolates $(80.60 \%)$ were proved to be enterotoxin producers and caused accumulation of fluids in the intestinal tract of inoculated mice. This proved high correlation between isolation of enterotoxigenic E. coli and induction of diarrhea. Such finding is supported by (Al Majali et al., 2000 and Tanois et al., 2000) who concluded that pathogenic E. coli usually causes diarrhea either by elaboration of enterotoxins or invasion of the intestinal mucosa.

Among the 31 isolated E. coli strains, 28 $(90.30 \%)$ were able to produce verotoxins and were pathogenic to vero cells, (Table 3 ). This was in agreement with that reported by (Ball et al., 1994).

In conclusion the present study demonstrated the correlation between the presence of different virulence factors in E. coli isolates including congored activity, serum resistance, enterotoxin production and verotoxin activity and its pathogenicity in newborn calves. The results also indicated that E. coli continous to be a major problem causing a high morbidity and mortality leading to severe economic losses among calves. Due to the increased prevalence of E. coli infection among calves, it is recommended to establish a good passive protection in enzootic areas, which can be achieved by feeding calves on milk from immunized dams.

\section{References}

Adel, S. A.; Ahmed, S. A.; Goda, F. F. and Abdel Hameed, M. M. (1987): The role of Enterobacteriaceae group in enteritis of buffalo calves. M.V.SC. Animal and Fish Disease, Fac. of Vet. Med. Cairo Univ., Egypt.

Adesyun, A. A.; Kaminjolo, J. S.; Ngeleka, M.; Mutani, A.; Borde, G.; Hare wood, W. and Harper, W. (2001): A longitudinal study on enteropathogenic infections of livestock in Trinidad. Revista-da - Sociedade - Brasileria de - Medicina - Tropical 34 (1): 29-35.

Al-Majali, A. M.; Asem, E. K.; Lamar, C. H.; Robinson, J. P.; Freeman, M. J. and Saeed. A. M. (2000): Characterization of the interaction of $E$. coli heat-stable enterotoxin 